\title{
Técnicas de predicción de ciclones y tormentas tropicales sobre el mar Arábigo y el golfo de Adén
}

\author{
Beatriz Sanz Fernández-Cuevas ${ }^{1}$ (bsanzf@aemet.es) \\ José Félix Chinchón Bengoechea ${ }^{1}$ (fchinchonb@aemet.es) \\ Irene Mestre Guillén ${ }^{1}$ (imestreg@aemet.es)
}

${ }^{1}$ AEMET / Dirección de Producción e Infraestructuras / Centro Nacional de Predicción para la Defensa

\begin{abstract}
RESUMEN
Los ciclones tropicales con origen en el mar Arábigo que entran en el golfo de Adén son extremadamente raros. En los últimos 60 años, solo tres ciclones se han adentrado en el golfo de Adén, todos posteriores al año 2015. Esta primavera, un ciclón tropical se adentró en el golfo de Adén, donde en ese momento se llevaba a cabo una operación militar. En este trabajo se analiza la forma en la que se realizó el seguimiento del ciclón, gracias al cual no se produjeron heridos, ni daños en las fragatas y helicópteros que participaban en la misión.
\end{abstract}

PALABRAS CLAVE: ciclón tropical; mar Arábigo; Defensa; seguimiento.

\section{INTRODUCCIÓN}

En los últimos 30 años en el mar Arábigo se han registrado 46 ciclones, de los cuales 23 han tocado tierra, 8 de ellos fueron muy severos y uno fue un superciclón, con vientos de más de 120 nudos. En los últimos 60 años solo 3 ciclones han tocado tierra en la península arábiga y hasta 2015 ninguna tormenta tropical se había adentrado en el golfo de Adén, habiéndose dado tres casos desde entonces.

Esta primavera, Defensa organizó una operación de diplomacia, en el marco de la cual se llevó a cabo una misión en la que participaban diversas fragatas, que debían descender por el mar Rojo y atravesar el golfo de Adén. Cuando se encontraban en tránsito por el mar Rojo, un ciclón tropical se formó en el mar Arábigo y su trayectoria prevista era entrar en el golfo de Adén, encerrando a los barcos y helicópteros, con el gran peligro que esto conllevaría para los efectivos de la misión. Gracias a un buen seguimiento del ciclón y una comunicación ágil entre Defensa y AEMET, los barcos pudieron dejar atrás el ciclón. Esto ha supuesto un gran éxito para AEMET.

\section{CLIMATOLOGÍA DE LOS CICLONES TROPICALES EN EL MAR ARÁBIGO}

El mar Arábigo se encuentra en la costa suroccidental de Asia, entre la península arábiga y la península del Indostán, y forma parte del océano Índico. En el mar Arábigo la frecuencia de aparición de ciclones tropicales es relativamente baja (dos ciclones al año en promedio). No obstante, ocasionalmente alguna tormenta intensa toca tierra.

La tormenta más potente registrada en los últimos tiempos fue la super tormenta ciclónica Gonu en 2007. Se formó a principios de junio y alcanzó las costas de Omán e Irán, causando daños valorados en 4 millones de dólares estadounidenses y un total de 100 víctimas mortales en Omán, Irán y los Emiratos Árabes Unidos. 


\subsection{Los ciclones tropicales en el mar Arábigo}

La distribución anual de las tormentas que se forman en el mar Arábigo presenta un ciclo bimodal con máximos en primavera y otoño y dos mínimos en verano e invierno respectivamente (EvAN y CAMARGO, 2010). El descenso de la ciclogénesis en los meses de julio y agosto se debe fundamentalmente a la fuerte cizalladura vertical del viento en esa época del año. Esta cizalladura es debida a la intensidad de los vientos del este en altura y al desplazamiento estacional de la vaguada monzónica sobre el subcontinente indio, que produce fuertes vientos del suroeste y oeste en niveles bajos.

La ciclogénesis que ocurre en el mes de mayo está relacionada con las condiciones atmosféricas coincidentes con un comienzo temprano del monzón mientras que la ciclogénesis de junio se relaciona con un comienzo tardío del monzón. La actividad de noviembre está relacionada con anomalías de presión sobre el golfo de Bengala, lo cual implica la formación preferente de tormentas en el mar Arábigo o en el golfo de Bengala pero no simultáneamente en las dos zonas.

Las tormentas tienden a formarse en el periodo de avance de la vaguada monzónica hacia el norte en primavera y en su retroceso en verano. Las condiciones de cizalladura al norte de la vaguada son las adecuadas para la formación de ciclones cuando dicha vaguada se encuentra entre $5^{\circ} \mathrm{N}$ y $10^{\circ} \mathrm{N}$.

La mayor parte de los ciclones del mar Arábigo se forman en las proximidades de la costa occidental de la India y siguen una trayectoria hacia el norte. También se forman ciclones en el centro del mar Arábigo, que se desplazan siguiendo una trayectoria más orientada hacia el oeste.

Se puede obtener una estimación anual del promedio de días de tormenta ciclónica, considerando el número de tormentas cuyos vientos superan los $35 \mathrm{kt}$ (EvAN y CAMARGO, 2010), contabilizando el número de días que dura cada una de estas tormentas. Los resultados corroboran la distribución bimodal, mencionada anteriormente. El promedio de días de tormenta ciclónica anuales es de 4,7. En los últimos años el número de días de tormenta ha aumentado, fundamentalmente debido al aumento del número de tormentas más que a su duración (ElsNer et al., 2008). No es posible demostrar que este aumento sea debido a causas físicas.

Otro parámetro utilizado en relación con los ciclones tropicales es la energía ciclónica acumulada (ECA). La ECA para un determinado periodo se calcula como la suma de los cuadrados de cada estimación de la velocidad máxima sostenida de los ciclones tropicales, a intervalos de seis horas. La ACE, ya sea anual o mensual, depende del número de tormentas, de su duración y de la intensidad.
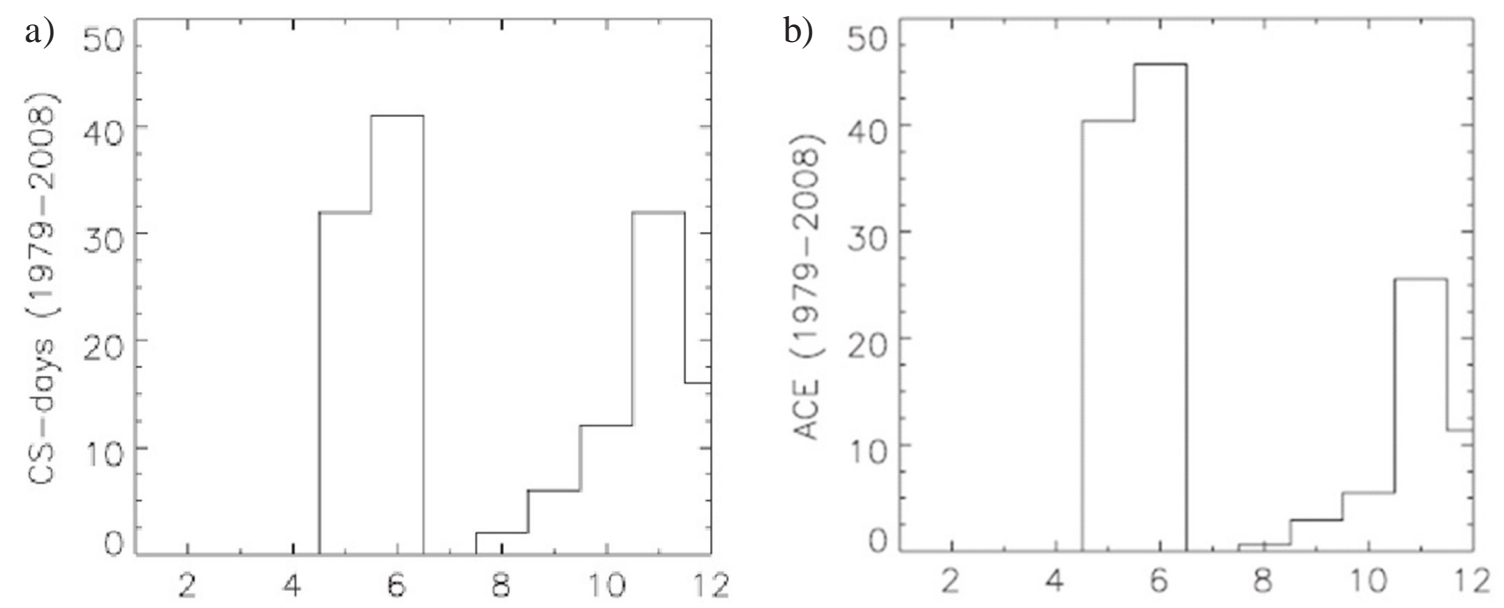

Figura 1. a) Frecuencia mensual del número de días de tormentas ciclónica en el periodo 1979-2008. b) Energía ciclónica acumulada media mensual (en $\mathrm{kt}^{2}$ ) en el periodo 1979-2008. 
Los valores promedio de la ACE han aumentado en los 30 años de estudio desde $2,2 \mathrm{kt}^{2}$ en la primera mitad de la serie hasta los 8,2 kt ${ }^{2}$ de la segunda mitad. Este aumento se debe principalmente a la aportación de cuatro tormentas premonzónicas intensas: TC 03A (junio de 1998), TC 02A (mayo de 1999), TC 01A (mayo de 2001) y Gonu (junio de 2007). En este caso, tampoco se puede asegurar que haya una causa física detrás de este aumento.

A la hora de estudiar la formación de tormentas tropicales también es importante tener en cuenta el ciclo anual de distribución de la cizalladura vertical, fundamental para entender el patrón anual de formación de ciclones.

Se define la cizalladura vertical como aquella entre las capas de $925-700 \mathrm{hPa}$ y 200-150 hPa. En el mar Arábigo, la cizalladura sigue el comportamiento del viento en $200 \mathrm{hPa}$. En el periodo diciembre-abril, aproximadamente, el flujo de la troposfera superior está dominado por el chorro subtropical del oeste. Durante los meses cálidos el flujo en altura está dominado por el chorro tropical del este. Los meses de mayor cizalladura también son los de menor ciclogénesis.

\subsection{Influencia del monzón del suroeste en la formación de ciclones tropicales}

El monzón del suroeste domina gran parte de la meteorología del mar Arábigo en verano. Así mismo, el aumento de la cizalladura de los meses de julio y agosto impide la intensificación de las tormentas en esos meses. Algunos autores sostienen que la disminución de la temperatura del mar de esos meses no tiene ninguna influencia en la formación de tormentas en ese periodo.

El monzón del suroeste está asociado a la corriente de bajo nivel del suroeste de la costa este del norte de África ecuatorial (jet somalí o chorro de Somalia) y al flujo del sur transecuatorial en el océano Índico occidental (Evan y CAMARGo, 2010). La intensidad de los vientos del suroeste (entre mayo-junio y octubre), produce un transporte neto de agua superficial hacia el interior del océano desde África oriental y la península Arábiga, y un afloramiento de aguas profundas a la superficie durante el periodo monzónico. Este enfriamiento hace que la variación de las temperaturas de la superficie marina (figura 2) también sea bimodal, con máximos relativos de las temperaturas en mayo (absoluto) y en octubre (relativo) y mínimos en julio y enero, con valores similares. El enfriamiento del mar Arábigo solo es intenso en las zonas próximas de la costa, manteniéndose la temperatura en la mayor parte del océano (incluidas las zonas de ciclogénesis) por encima de los $26,5^{\circ} \mathrm{C}$, que es el valor límite para la formación de ciclones tropicales.

a)

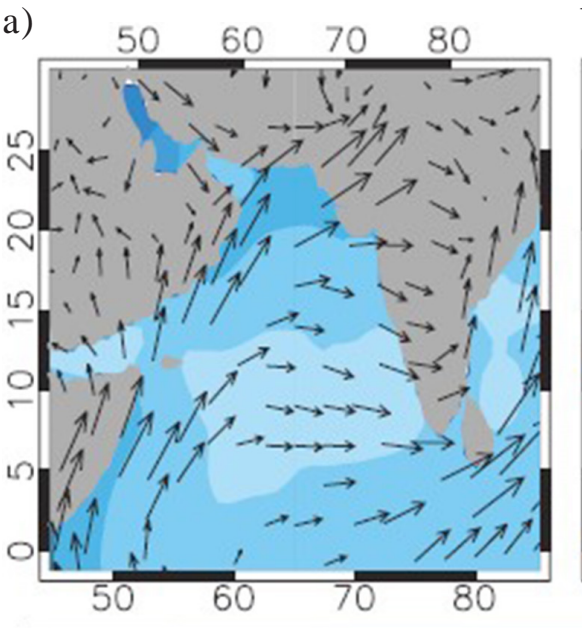

b)
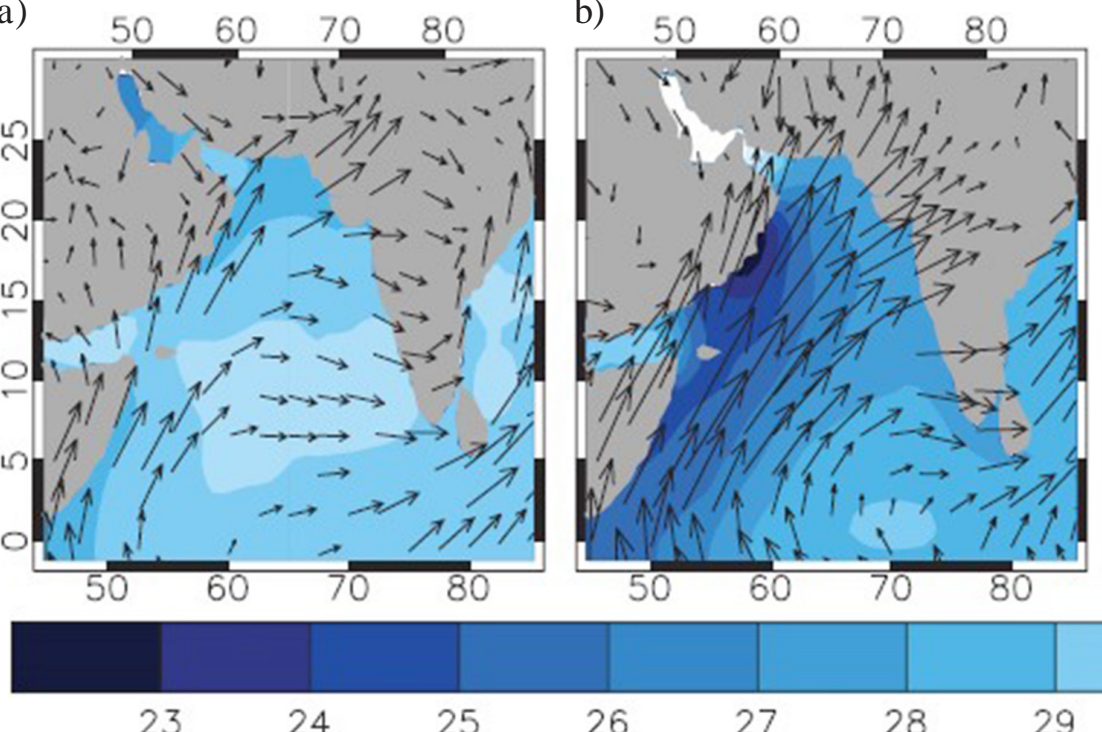

23

24

25
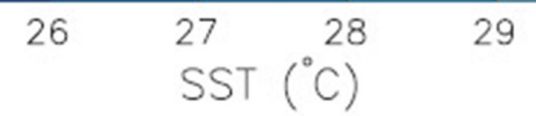

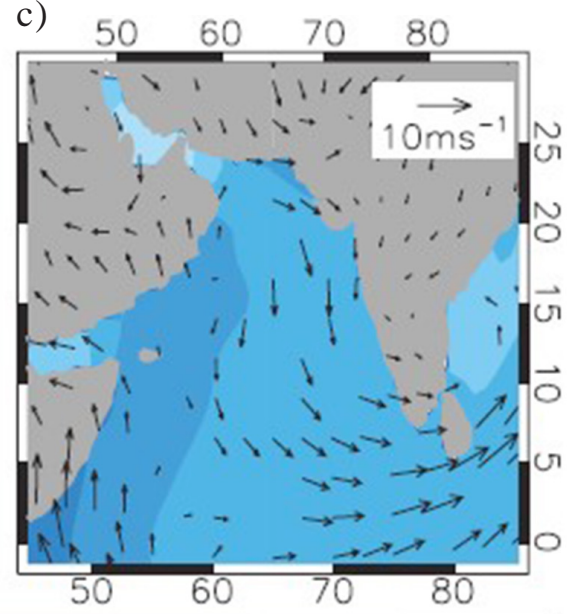

c)

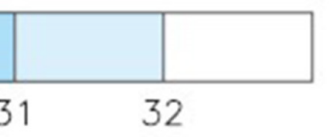

Figura 2. Temperatura de la superficie del mar en a) mayo, b) agosto y c) octubre. 
El chorro de Somalia tiene un desplazamiento latitudinal a lo largo del año, situándose muy cerca del ecuador en su lado norte en primavera y otoño y en su posición más septentrional durante julio-agosto. La vorticidad relativa a niveles bajos $(925-700 \mathrm{hPa})$ es negativa al sur del chorro de Somalia y positiva norte (figura 3).

La distribución de estos valores de vorticidad junto con los de temperatura del mar explica la variación de ciclogénesis a lo largo del año. Por ejemplo, en los meses de julio y agosto, el chorro está en su posición más al norte dejando los valores de vorticidad positivos en las zonas donde la temperatura superficial es menor. Durante los meses pre y postmonzónicos el chorro está situado muy cerca del ecuador, dejando amplias zonas con vorticidad positiva, en zonas de temperaturas superficiales altas, que son zonas con potencial para el desarrollo de tormentas.

El mar Arábigo es una región con grandes entradas de polvo atmosférico que se originan tanto en la península arábiga como en Irán-Pakistán. Algunos autores creen que el polvo atmosférico puede afectar al monzón del suroeste a través del llamado efecto de bomba del calor en altura, aunque la importancia del polvo mineral en el mar Arábigo no está demostrada.
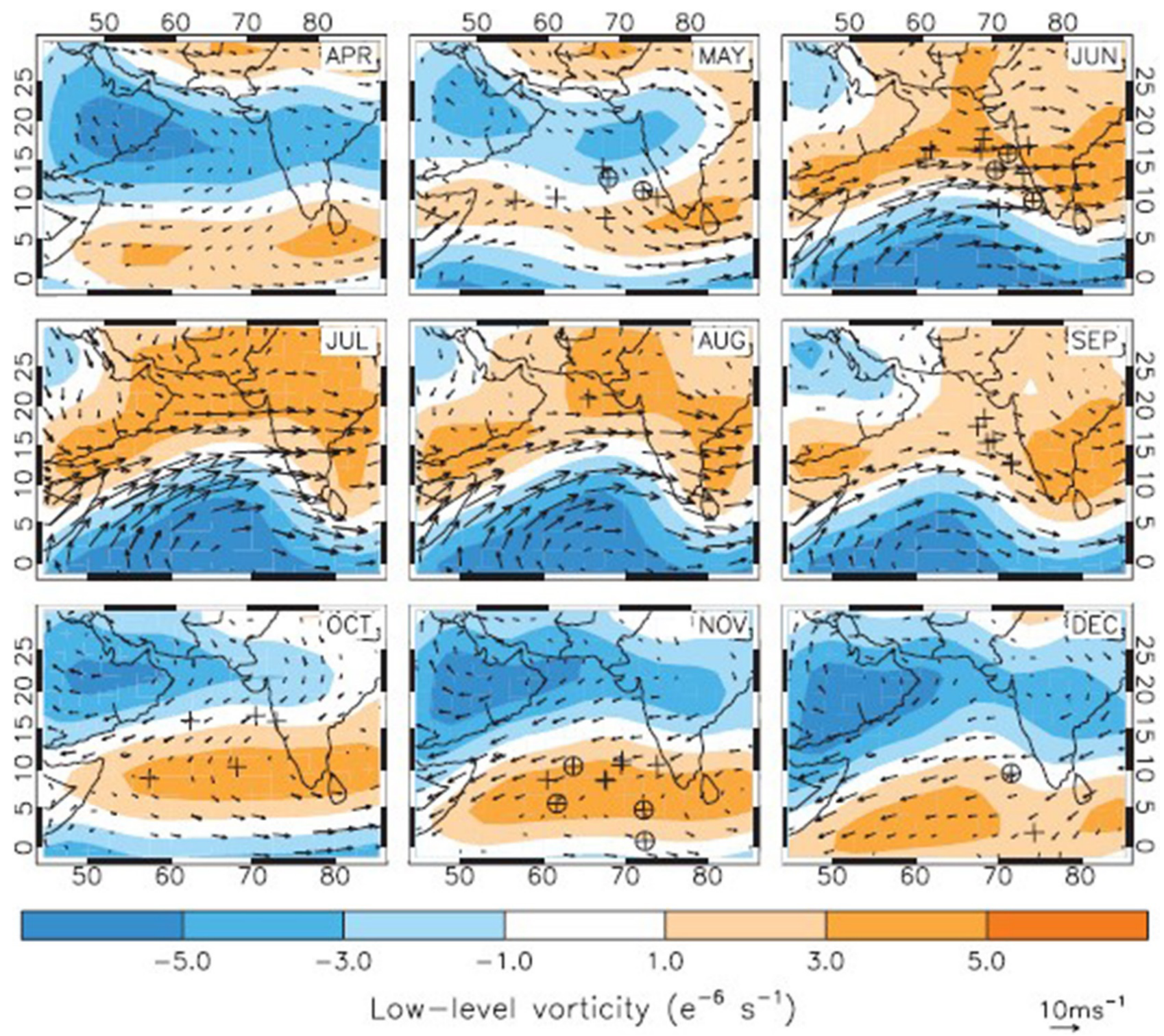

Figura 3. Vorticidad relativa media en niveles bajos para los distintos meses del año. 


\section{CASO DE ESTUDIO}

Esta primavera, Defensa organizó una operación de diplomacia, que constaba a su vez de tres misiones. En esta operación participaba el portaaviones Juan Carlos I, acompañado de 2 fragatas, a bordo de los cuales iban embarcados 8 aviones reactores Harrier. También transportaban 20 helicópteros del ejército de tierra, que debían desembarcar en Kuwait, y unos 2000 militares españoles.

Esta misión tenía un doble propósito, uno relacionado con Defensa, y otro de relaciones internacionales, puesto que durante su trayecto por el Mediterráneo iba a llevar a cabo diferentes ejercicios con otros países europeos (en el marco de las operaciones Sofía, Atalanta, etc.). Después de estos ejercicios, los barcos debían atracar en Kuwait.

La operación de diplomacia partió el día 1 de mayo de la península ibérica, y atravesó el mar Mediterráneo. El día 9 de mayo la operación diplomática se encontraba empezando a cruzar el canal de Suez para adentrarse en el mar Rojo, con el fin de cumplir su misión. La misión debía recorrer el mar Rojo, hasta el estrecho de Bab al-Mandab. Después debía recorrer el golfo de Adén, bordeando Yemen y Omán, para adentrarse en el golfo de Omán, y el golfo Pérsico, para llegar a Kuwait el día 20 de mayo.

Durante el periodo del 1 al 8 de mayo, la situación meteorológica fue favorable para la misión. Sin embargo, el Dust Forecast Center, en su pasada del martes 8 de mayo, predijo una importante entrada de polvo en la zona norte del mar Rojo durante la tarde del 10 de mayo. A su vez, el Centro Europeo predijo vientos de 30 nudos en la zona que, unidos a la gran cantidad de polvo en suspensión, producirían una tormenta de arena de grandes proporciones, que según las previsiones alcanzaría al portaaviones.

Así mismo, el miércoles 9 de mayo, el modelo del Centro Europeo predijo la formación de un ciclón tropical para el martes 15 al este de la isla de Socora (tanto en el modelo determinista como en el de control), que parecía impactar sobre el golfo de Omán. Sin embargo, el modelo GFS no predecía la formación de ningún ciclón en esas fechas. Se informó de esta situación al Mando de Operaciones del Ejército.

El jueves 10 de mayo, el portaaviones se encontraba en la zona norte del mar Rojo, dentro de la tormenta de arena. Ese mismo día, el Centro Europeo, en su pasada de las $12 \mathrm{Z}$, marcaba un crecimiento del ciclón e indicaba que el ciclón iba a adentrarse en el golfo de Adén. Cabe destacar que durante los últimos 60 años solo un ciclón se había adentrado antes en el golfo de Adén. El día 10, el modelo del GFS seguía sin ver este ciclón.

El principal problema de la misión era decidir si los barcos debían o no cambiar el rumbo, dado que, si continuaban con el rumbo previsto y las previsiones del Centro Europeo se cumplían, los barcos iban a quedar encerrados por el ciclón.

El sábado 12 y el domingo 13 de mayo, el modelo del Centro Europeo disolvió el ciclón y el GFS seguía sin predecirlo, por lo que parecía tratarse de una falsa alarma. Sin embargo, el lunes 14 el ciclón vuelve a aparecer en el modelo del Centro Europeo y el modelo del GFS ve por primera vez una perturbación. La misión se encontraba en ese momento en las costas de Djibuti y la posición prevista para el miércoles 16 a las $12 \mathrm{Z}$ coincidía con la posición en la que se encontraría el ciclón. Además, el modelo situaba el impacto del ciclón el sábado a las 12 Z en Djibuti, donde se encontraba otra operación del ejército, la operación Orión. El mismo lunes 14, la OTAN había empezado a desplazar todos sus barcos hacia Madagascar debido al ciclón.

Finalmente, el miércoles 16 a las 0:00 Z, el ciclón, bautizado como SAGAR, se encontraba en la entrada del golfo de Adén, y los barcos salieron del golfo, dejando el centro del ciclón a 50 millas. La previsión a las 0:00Z era que el ciclón impactase en Djibuti, pero en la pasada de las $12 \mathrm{Z}$ la trayectoria se desvió hacia la frontera, donde realmente impactó. El seguimiento del ciclón fue un gran éxito de AEMET, y la Armada así lo reconoció. 


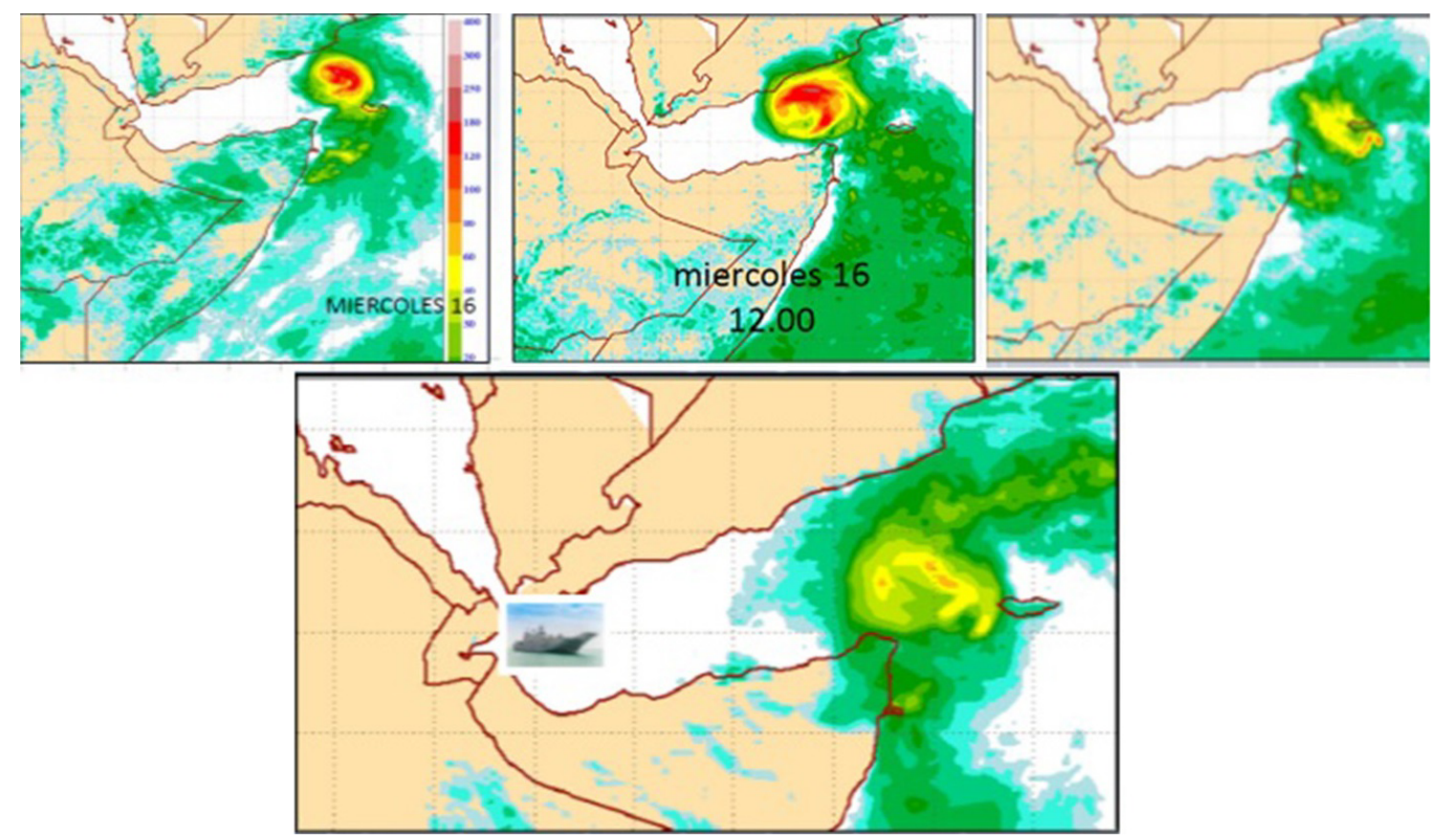

Figura 4. Precipitación prevista del ECMWF los días 9, 10, 11 y 13 de mayo para el día 16 de mayo.

\section{CONCLUSIONES}

En el caso de estudio que se ha presentado queda patente la necesidad de los servicios meteorológicos de contar con una buena predicción y seguimiento de los ciclones. Gracias al buen seguimiento del ciclón y a que se cumplieron las predicciones que se realizaron utilizando el modelo del Centro Europeo, el barco que se encontraba cerca del ciclón consiguió rodearlo y evitar cuantiosas pérdidas económicas, daños materiales y no se produjeron heridos.

Para poder predecir acertadamente los ciclones y dar un buen seguimiento de los mismos, es esencial contar con modelos numéricos precisos y buenas herramientas. En este caso, el modelo del Centro Europeo reprodujo de forma muy acertada el desarrollo del ciclón y su trayectoria.

Asimismo, cabe destacar que los últimos años la colaboración entre AEMET y las fuerzas armadas se ha estrechado, permitiendo un intercambio más ágil de la información entre ambos, y permitiendo un mejor seguimiento de las situaciones meteorológicas potencialmente peligrosas en los lugares donde se desarrollan las misiones militares.

\section{REFERENCIAS}

ELSNER, J. B. et al., 2008. The increasing intensity of the strongest tropical cyclones. Nature, 455, 92-95.

Evan, A. T. y CAmargo, S. J., 2010. A Climatology of Arabian Sea Cyclonic Storms. Journal of Climate, 24, 140-158. 